\title{
The way early-onset chronically depressed patients are treated today makes me sad
}

\author{
James P. McCullough
}

Department of Psychology, Virginia Commonwealth University, Richmond, USA

Email:jmccull@vcu.edu

Received 4 December 2011; revised 2 January 2012; accepted 12 January 2012

\begin{abstract}
The author has treated almost 400 chronically depressed outpatients during his career. He has also participated as a Field Trial Coordinator in the Unipolar Field Trials of DSM-IV and consulted with the DSM-V Mood Disorders Workgroup concerning his research for the new diagnostic nomenclature for the chronic depressions, Chronic Depression Disorder. In addition, he has served as Principal Investigator in several large clinical trials involving 2200 chronically depressed outpatients. The current paper is a Brief Report describing his negative reactions to the way 40 of his chronically depressed patients have been treated today by both Psychologists and Psychiatrists. All the patients are his patients and have been seen by him in psychotherapy over the past decade. Several reasons are proposed for the inadequate treatment and specific proposals are made for the improvement of treatment for the early-onset chronically depressed patient.
\end{abstract}

Keywords: CBASP Psychotherapy; DSM-V Chronic Depression Disorder; Combination Treatment; Early-Onset Chronic Depression

\section{INTRODUCTION}

When I diagnose an adult with early-onset chronic depression disorder [1], he or she must have been continuously depressed since childhood or adolescence. This means that when most patients come to my office they have been depressed for several decades. There are 11 million such individuals in the US today and they cost our nation about $\$ 45$ billion annually. I am a Professor of Psychology and Psychiatry at Virginia Commonwealth University and have treated almost 400 early-onset patients during my career. Since 2001, I've treated four-to-five early onset-chronic patients weekly in my University office. My recent treatment experiences with these 40 patients motivated me to write this article.
What I've heard in their treatment histories are stories of repeated trials of ineffective psychotherapy and pharmacotherapy all of which are usually accompanied by the statement: "Nothing ever helped resolve my depresssion in any significant way." Out of the 40 patients I've treated since 2001, not one has been treated adequately. What's going on here? Several things:

1) Misdiagnosis is a major problem today. Practitioners frequently overlook when the depressive disorder began and administer treatment based on the current depressive status of the patient. When chronicity is missed, the outcome usually results in inadequate treatment. Most chronic patients experienced their first depression during early adolescence and the diagnosis is usually dysthymia, a mild-moderate type of chronic depression that is a lifetime disorder unless treated properly [2]. More importantly, dysthymia is often predictive of a destructive developmental history that implicates a dysfunctional home life. Sexual abuse, physical abuse, emotional deprivation or the presence of continuous psychological insults often accompany a dysthymia diagnosis.

2) A second problem arises when early-onset chronicity is overlooked. In missing the early roots of the patient's dilemma, psychotherapy fails because clinicians do not address the disastrous and crippling early developmental experiences. One patient who grew up in a home where he was beaten regularly by his father had been instructed by his Psychologist to chant multiple times a day: "I will feel better, I will feel better" and not surprisingly, he didn't; another female patient, the victim of a serious 11-year sexual abuse history, was encouraged to think more positively and relinquish her negative beliefs about the world; a third was told that she would just have to get used to being depressed-there was nothing anyone could do for her. The results of such treatment are poor outcomes.

I've also never treated an early-onset patient who hasn't been prescribed numerous drugs. The drugs were usually administered by Psychiatrists. Practitioners who rely on antidepressant medication alone with this population are betting on a long-shot-approximately $30 \%$ will 
fully respond [3-6]. We still know very little about how these drug-alone patients fare over time. The ones I've seen haven't fared well.

The usual experience with drug-alone treatment is that one drug doesn't work very well. Thus, augmenting the drug with additional ones or switching to different medicines is undertaken; sleep medication is frequently added because of insomnia problems (a common problem with depression), and I frequently encounter patients who've been prescribed an anti-anxiety medicine for psychological tension. It's common for me to begin psychotherapy with patients who are taking 4 - 5 medications dailynone of which has reduced the depressive symptoms. Of late, I'm finding patients who've been prescribed two antipsychotic medicines for chronic depression: seroquel (quetiapine fumarate) and geodon (ziprasidone) for insomnia. Both seroquel and geodon may result in tardive dyskinesia, an involuntary and irreversible neurological disorder, when taken over time. I recently persuaded one of my patients to stop taking seroquel after speaking to the Psychiatrist who refused to stop prescribing the drug. This female was exhibiting involuntary mouth spasms, the beginning signs of facial motor dyskinesia.

3) The third problem is also related to the first one and occurs because the diagnostic term, chronic depression disorder, is a johnny-come-lately to the psychiatric diagnostic nomenclature. The next edition of the American Psychiatric Association's Diagnostic \& Statistical Manual (DSM-5th Edition to be published in May, 2013) [1] will include for the first time a new diagnostic category, Chronic Depression Disorder. Not only is the category new to our field, most psychological and psychiatric workers as yet do not know much about the unique developmental issues of this patient.

Summarily, medicine used alone is more often than not an inadequate treatment approach for chronic depresssion. Medicine should always be combined with effective psychotherapy [3]. During the early stages of psychotherapy, the psychotherapist must be aware of the severe cognitive and emotional problems of the patient due to his or her destructive developmental history. Normal cognitive and emotional maturation may be inhibited in maltreatment environments because "surviving the hell of the family," not growth, is the order of the day. Two palpable maltreatment consequences are carried into adulthood. They are the following: 1) the first consequence is a pervasive fear of other people coupled with a socially avoidant lifestyle; 2) the second is a generalized perceptual disengagement from the social environment that precludes one from benefiting from interpersonal feedback [7-9]. As illogical as it sounds, the early-onset chronically depressed patient lives in a solitary world of intrapersonal sameness devoid of a future: the present is a replay of a hurtful past and the future bodes only more of the same pain.

\section{WHAT CAN BE DONE}

The traditional psychotherapy role with the chronic patient is typically one-way. I mean by this that most psychotherapists remain shrouded behind a wall of professionalism and the patient is the one who discloses and talks about personal matters. This type of interaction is best described as a sort of "I get to know you but you don't get to know me" relationship. Most psychotherapists try to be empathic and understanding, but patients whose significant others have been either severely hurtful or neglecting need more than the usual empathy and understanding. They need to encounter an authentic human being who is not afraid to be himself or herself nor afraid to walk with the patient as a "comrade" as is done in CBASP psychotherapy [8-10]. Some patients I've worked with tell me that they've never encountered a decent human being before-at least one whom they could come to trust and not fear. I've found that I must teach patients how to behave interpersonally with me and help them become cognizant of the interpersonal effects they personally have on me. This process allows for the discovery of a new relational reality and evokes a feeling of interpersonal safety. I cannot do this practicing a traditional one-way professional role.

The second thing that must be accomplished in psychotherapy is to perceptually connect early-onset patients to the social environments within which they live so that they come to recognize that their behavior has specific effects on others. This is usually an empowering experience because their felt helplessness is undercut by a growing awareness that everything they do with others has effects! This opens the patient up to informing and salubrious interpersonal feedback.

My desire in writing this article is to help make professionals and the public aware of the need for therapeutic improvement in the treatment of the early-onset chronically depressed patient. More effective treatment may offer hope to a patient population which desperately needs all the hope it can get.

\section{REFERENCES}

[1] American Psychiatric Association (APA) (in press, May 2013) Diagnostic \& statistical manual of mental disorders. 5th Edition, American Psychiatric Association, Washington, DC.

[2] Klein, D.N., Shankman, S.A. and Rose, S. (2006) Tenyear prospective follow-up study of the naturalistic course of dysthymic disorder and double depression. American Journal of Psychiatry, 163, 872-880. doi:10.1176/appi.ajp.163.5.872

[3] Keller, M.B., Gelenberg, A.J., Hirschfrield, R.M.A., Rush, 
A.J., Thase, M.E., Kocsis, J.H., Markowitz, J.C., Fawcett, J.A. Koran, L.M., Klein, D.N., Russell, J.M., Kornstein, S.G., McCullough, J.P. Jr., Davis, S.M. and Harrison, W.H. (1998) The treatment of chronic depression, part 2: A double-blind, randomized trial of sertraline and imipramine. Journal of Clinical Psychiatry, 59, 598-607. doi:10.4088/JCP.v59n1107

[4] Keller, M.B, McCullough, J.P., Jr., Klein, D.N., Arnow, B., Dunner, D.L., Gelenberg, A.J., Markowitz, J., Nemeroff, C.B., Russell, J.M., Thase, M.E., Trivedi, M. and Zajecka, J. (2000) A comparison of nefazodone, the Cognitive Behavioral Analysis System of Psychotherapy, and their combination for the treatment of chronic depression. New England Journal Medicine, 342, 1462-1470. doi:10.1056/NEJM200005183422001

[5] Kocsis, J.H., Gelenberg, A.J., Rothbaum, B.O., Klein, D.N., Trivedi, M.H., Manber, R., Keller, M.B., Leon, A.C., Wisniewski. S.R., Arnow, B.A., Markowitz, J.C. and Thase. M.E. (2009) Cognitive Behavioral Analysis System of Psychotherapy and Brief Supportive Psychotherapy for augmentation of antidepressant nonresopnse in chronic depression. Archives of General Psychiatry, 66, 1178-1188. doi:10.1001/archgenpsychiatry.2009.144

[6] Rush, A.J., Trivedi, M.H., Wisniewski, S.R., Nierenberg,
A.A., Stewart, J.W., Warden, D., Niederehe, G., Thase, M.E., Lavori, P.W., Lebowitz, B.D., McGrath, P.J., Rosenbaum, J.F., Sackeim, H.A., Kupfer, D.J., Luther, J. and Fava, M. (2006) Acute and longer-term outcomes in depressed outpatients requiring one or several treatment steps: A STAR*D report. American Journal of Psychiatry, 163, 1905-1917. doi:10.1176/appi.ajp.163.11.1905

[7] McCullough, J.P. Jr., Lord, B.D., Conley, K.A. and Martin, A.A. (2010) A method for conducting intensive psychological studies with early-onset chronically depressed patients. American Journal of Psychotherapy, 64, 317337.

[8] McCullough, J.P. Jr., Lord, B.D., Martin, A.A., Conley, K.A., Schramm, E. and Klein, D.N. (2011) The significant other history: An interpersonal-emotional history procedure used with the early-onset chronically depressed patient. American Journal of Psychotherapy, 65, 225-248.

[9] McCullough, J.P. Jr., (2000) Treatment for chronic depression: Cognitive Behavioral Analysis System of Psychotherapy. Guilford, New York.

[10] McCullough, J.P. Jr., (2006) Treating chronic depression using disciplined personal involvement: Cognitive Behavioral Analysis System of Psychotherapy. Springer, New York. 